\title{
Metreleptin-mediated improvements in insulin sensitivity are independent of food intake in humans with lipodystrophy
}

\author{
Rebecca J. Brown, ${ }^{1}$ Areli Valencia, ${ }^{1}$ Megan Startzell, ${ }^{1}$ Elaine Cochran, ${ }^{1}$ Peter J. Walter, ${ }^{2}$ H. Martin Garraffo, ${ }^{2}$ Hongyi Cai, ${ }^{2}$ \\ Ahmed M. Gharib, ${ }^{3}$ Ronald Ouwerkerk, ${ }^{3}$ Amber B. Courville, ${ }^{4}$ Shanna Bernstein, ${ }^{4}$ Robert J. Brychta, ${ }^{1}$ Kong Y. Chen, ${ }^{1}$ \\ Mary Walter, ${ }^{5}$ Sungyoung Auh, ${ }^{6}$ and Phillip Gorden ${ }^{1}$
}

'Diabetes, Endocrinology, and Obesity Branch (DEOB), National Institute of Diabetes and Digestive and Kidney Diseases (NIDDK), NIH, Bethesda, Maryland, USA. ${ }^{2}$ Clinical Mass Spectrometry Core and ${ }^{3}$ Biomedical and Metabolic Imaging Branch, NIDDK, NIH, Bethesda, Maryland, USA. ${ }^{4}$ Nutrition Department, Clinical Center, NIH, Bethesda, Maryland, USA. ${ }^{5}$ Clinical Core Laboratory and ${ }^{6}$ Office of the Clinical Director, NIDDK, NIH, Bethesda, Maryland, USA.

\begin{abstract}
BACKGROUND. Recombinant leptin (metreleptin) ameliorates hyperphagia and metabolic abnormalities in leptin-deficient humans with lipodystrophy. We aimed to determine whether metreleptin improves glucose and lipid metabolism in humans when food intake is held constant.
\end{abstract}

METHODS. Patients with lipodystrophy were hospitalized for 19 days, with food intake held constant by a controlled diet in an inpatient metabolic ward. In a nonrandomized, crossover design, patients previously treated with metreleptin $(n=8)$ were continued on metreleptin for 5 days and then taken off metreleptin for the next 14 days (withdrawal cohort). This order was reversed in metreleptin-naive patients $(n=14)$, who were reevaluated after 6 months of metreleptin treatment on an ad libitum diet (initiation cohort). Outcome measurements included insulin sensitivity by hyperinsulinemic-euglycemic clamp, fasting glucose and triglyceride levels, lipolysis measured using isotopic tracers, and liver fat by magnetic resonance spectroscopy.

RESULTS. With food intake constant, peripheral insulin sensitivity decreased by $41 \%$ after stopping metreleptin for 14 days (withdrawal cohort) and increased by $32 \%$ after treatment with metreleptin for 14 days (initiation cohort). In the initiation cohort only, metreleptin decreased fasting glucose by $11 \%$ and triglycerides by $41 \%$ and increased hepatic insulin sensitivity. Liver fat decreased from $\mathbf{2 1 . 8} \%$ to $\mathbf{1 8 . 7 \%}$. In the initiation cohort, changes in lipolysis were not independent of food intake, but after 6 months of metreleptin treatment on an ad libitum diet, lipolysis decreased by $30 \%$ (palmitate turnover) to $35 \%$ (glycerol turnover).

CONCLUSION. Using lipodystrophy as a human model of leptin deficiency and replacement, we show that metreleptin improves insulin sensitivity and decreases hepatic and circulating triglycerides and that these improvements are independent of its effects on food intake.

TRIAL REGISTRATION. ClinicalTrials.gov NCT01778556

FUNDING. This research was supported by the intramural research program of the NIDDK.

\section{Introduction}

Leptin is an adipocyte-derived hormone that signals overall body energy sufficiency (1) and acute energy balance (2). Leptindeficient states, such as starvation or mutations in the leptin gene,

Related Commentary: p. 3237

Conflict of interest: The authors have declared that no conflict of interest exists. Role of funding source: This study was supported by the intramural research program of the NIDDK. Metreleptin was donated for this study by Aegerion Pharmaceuticals, which had no role in the study design, conduct, or data analysis and interpretation, or in the decision to publish the study.

Submitted: October 9, 2017; Accepted: May 1, 2018.

Reference information: / Clin Invest. 2018;128(8):3504-3516.

https://doi.org/10.1172/JCI95476. lead to hyperphagia. Lipodystrophy is an additional leptin-deficient state, in which a deficiency of adipose tissue results in hypoleptinemia, which induces hyperphagia, with energy intake approximately $40 \%$ higher than would be expected (3). The excess caloric intake is stored as ectopic fat in liver and muscle, causing severe insulin resistance and diabetes, along with hypertriglyceridemia, low levels of HDL cholesterol (HDL-C), and nonalcoholic fatty liver disease (NAFLD) $(4,5)$. Therefore, patients with lipodystrophy can serve as both a model of leptin deficiency and replacement, as well as of metabolic disease that is analogous to, albeit more severe than, that seen in patients with obesity-associated metabolic syndrome.

Treatment with metreleptin, a recombinant analog of human leptin, in humans with lipodystrophy ameliorates hyperphagia, ectopic lipid storage, hypertriglyceridemia, insulin resistance, and reproductive dysfunction $(4,6-9)$. The reduction in food intake 




Fasting labs, hyperinsulinemic-euglycemic clamp, and tracer isotope dilution studies MRS imaging of liver and muscles DXA

Figure 1. Study design. The leptin initiation cohort was untreated for the first 5 days (period 1), and then metreleptin was given for the following 14 days (period 2). This order was reversed for the leptin withdrawal cohort. During the short-term study, an isocaloric diet was maintained in both cohorts to permit the study of the effects of metreleptin during constant energy and macronutrient intake. During both periods 1 and 2, the patients in both cohorts underwent a DXA scan, a hyperinsulinemic-euglycemic clamp, and an MRS-MRI scan. This was repeated at a 6-month follow-up visit only in patients in the initiation cohort, who were on an ad libitum diet.

is probably responsible for part of the observed improvements in glucose and lipid metabolism. Studies of leptin-treated ob/ob mice and n-SREBP-1c lipodystrophic mice showed an additional reduction in glucose and insulin levels compared with levels in pair-fed controls, suggesting that leptin has a hypoglycemic effect independent of its effects on food intake $(10,11)$. Whether leptin has these energy intake-independent effects in humans has not previously been determined.

Using lipodystrophy as a human model of leptin deficiency and replacement, we conducted a nonrandomized, crossover study to determine the energy intake-independent effects of leptin on glucose and lipid metabolism. We hypothesized that, during constant food intake, patients with lipodystrophy would have greater insulin sensitivity and reduced lipolysis during the leptin replacement period than in the leptin-deficient state. Patients with no prior exposure to metreleptin constituted the initiation cohort, and patients already undergoing metreleptin treatment prior to our study constituted the withdrawal cohort. All patients were hospitalized for 19 days, with energy and macronutrient intake held constant by a controlled diet in an inpatient metabolic ward during periods on and off metreleptin. The withdrawal cohort was on metreleptin for 5 days and off metreleptin for the next 14 days. This order was reversed in individuals in the initiation cohort, who were restudied after 6 months of metreleptin treatment on an ad libitum diet (Figure 1).

\section{Results}

\section{Study participants}

Twenty-five patients with lipodystrophy were enrolled in the study. The flow of participants in this nonrandomized, crossover study is shown in Figure 2. Of the 15 initiation subjects, 1 did not complete the study procedures for the short-term, controlled food intake portion of the study but completed the 6-month follow-up, and $1 \mathrm{com}$ pleted the short-term study but was excluded from analysis of the 6-month data because of noncompliance with the study drug. In the withdrawal cohort, 8 subjects completed the study and were included in the analysis. $\mathrm{ng} / \mathrm{dl}$, reflecting greater leptin insufficiency in patients with generalized lipodystrophy, and had an average of $7.7 \pm 4.7$ (range, 0.914.5) years of prior metreleptin treatment. None of the withdrawal cohort participants was taking insulin. We observed the expected relationship between fat mass and the log of endogenous leptin in the combined cohorts $\left(R^{2}=0.69, P<0.0001\right)$, with no difference according to sex, cohort (initiation versus withdrawal), or lipodystrophy type (generalized versus partial).

\section{Short-term effects of metreleptin independent of food intake}

Food intake, diet, and body composition. During the 19-day inpatient stay, the patients were required to consume all study-provided foods and forbidden to consume any outside foods. Any uneaten portions of the study diet were weighed, and uneaten nutrients were replaced at the next meal when possible. Energy intake and macronutrient content were successfully held constant in the off- versus on-metreleptin periods in both groups (Table 2). Furthermore, multivariate analyses showed that the effects of metreleptin on the outcome measures of interest were not significantly influenced by actual caloric intake during the off- or on-metreleptin periods in either cohort (Supplemental Table 1; supplemental material available online with this article; https://doi.org/10.1172/JCI95476DS1).

In the initiation cohort, body weight (BW) and fat mass significantly decreased by $0.7 \mathrm{~kg}$ and $0.3 \mathrm{~kg}$, respectively, after 2 weeks on metreleptin. We observed no change in $\mathrm{BW}$ or fat mass in the withdrawal cohort and no change in lean mass or body fat percentage in either group.

Peripheral insulin sensitivity was greater in patients on metreleptin therapy, independent of food intake, in both the initiation and withdrawal cohorts; increases in hepatic insulin sensitivity with short-term metreleptin therapy were independent of food intake in the initiation cohort only. In the initiation cohort, peripheral insulin sensitivity measured by hyperinsulinemic-euglycemic clamp increased from $4.4 \pm 2.3 \mathrm{mg} / \mathrm{kg}$ fat-free mass (FFM) per minute at the end of period 1 before metreleptin treatment to $5.8 \pm 2.2 \mathrm{mg} / \mathrm{kg}_{\mathrm{FFM}} / \mathrm{min}$ at the end of period 2 on metreleptin $(P=0.001)$ (Figure 3$)$. Likewise, in the withdrawal cohort, peripheral insulin sensitivity decreased from 10.9 




Figure 2. Study flow chart. A total of 25 subjects were enrolled in the study: 15 in the initiation cohort and 10 in the withdrawal cohort. In the initiation cohort, 1 subject did not have complete data collection for the short-term study but completed the long-term study, and 1 subject was excluded from final analysis of the long-term study because of noncompliance with metreleptin. In the withdrawal cohort, 1 subject withdrew, and another subject with type 1 diabetes was excluded from the analysis because of recurrent hypoglycemia during the short-term study.

$\pm 4.1 \mathrm{mg} / \mathrm{kg}_{\mathrm{FFM}} / \mathrm{min}$ at the end of period 1 on metreleptin to $6.4 \pm$ $1.8 \mathrm{mg} / \mathrm{kg}_{\mathrm{FFM}} / \mathrm{min}(P=0.01)$ at the end of period 2 after metreleptin withdrawal (Figure 3). The magnitude of the increase in insulin sensitivity in the on- versus off-metreleptin condition was greater in the leptin withdrawal cohort. In the withdrawal cohort, we found a correlation between the reduction in peripheral insulin sensitivity after metreleptin withdrawal and increases in fasting glucose $(P=$ 0.014) and C-peptide $(P=0.006)$.

In the initiation cohort, hepatic insulin sensitivity, measured as insulin-mediated suppression of hepatic glucose production (HGP), increased from $61 \% \pm 23 \%$ at the end of period 1 to $75 \% \pm$ $33 \%(P=0.008)$ at the end of period 2 (Figure 3$)$. Suppression of HGP did not change in the withdrawal cohort (Figure 3).

Changes in hepatic triglyceride content significantly predicted changes in both peripheral and hepatic insulin sensitivity with metreleptin in the initiation cohort only (Supplemental Tables 2 and 3). Moreover, changes in peripheral and hepatic insulin sensitivity with metreleptin in the initiation cohort were no longer statistically significant after adjustment for changes in hepatic triglyceride content. By contrast, we found that intramyocellular triglyceride content was not a significant predictor of either peripheral or hepatic insulin sensitivity in most models, and improvement in peripheral and hepatic insulin sensitivity with metreleptin remained statistically signifi- cant after adjustment for intramyocellular triglyceride content (Supplemental Tables 2 and 4). Changes in body composition did not predict changes in insulin sensitivity with metreleptin, and improvements in insulin sensitivity remained statistically significant after adjustment for body composition.

Decreases in fasting glucose and glucosuria with short-term metreleptin therapy were independent of food intake in the initiation cohort. In the initiation cohort, fasting glucose decreased

\section{Table 1. Baseline characteristics in the initiation and withdrawal cohorts}

$\begin{array}{lcc}\text { Clinical values } & \text { Initiation }(\boldsymbol{n}=\mathbf{5}) & \text { Withdrawal }(\boldsymbol{n}=\mathbf{8}) \\ \text { Type of lipodystrophy (generalized/partial) } & (3 / 12) & (8 / 0) \\ \text { Subtype of lipodystrophy } & 3 \text { CGL, 12 FPL } & 7 \text { CGL, 1 AGL } \\ \text { Sex (male/female) } & (3 / 12) & (3 / 5) \\ \text { Age (yr) } & 32 \pm 17 & 25 \pm 6 \\ \text { Race/ethnicity } & 9 \text { White, } 4 \text { Hispanic, } & 4 \text { White, } 2 \text { African American, } \\ & 1 \text { Asian, } 1 \text { other } & 2 \text { Hispanic } \\ \text { Endogenous leptin level (ng/dl) } & 9.5 \pm 10.2^{A} & 1.2 \pm 0.5^{A} \\ \text { Duration of metreleptin treatment prior to study (yr) } & 0 & 7.7 \pm 4.7 \\ \text { Subjects on insulin (\%) } & 71 & 0 \\ \text { Insulin dose (units/day, insulin users only) } & 225 \pm 136 & 0 \\ \text { No. of diabetes medications } & 1.6 \pm 1.2 & 0.4 \pm 0.5 \\ \text { No. of lipid medications } & 1.8 \pm 0.9 & 0.4 \pm 0.7\end{array}$

Data represent the mean \pm SD unless otherwise noted. CGL, congenital generalized lipodystrophy; FPL, familial partial lipodystrophy; ACL, acquired generalized lipodystrophy. ${ }^{A}$ Endogenous leptin levels were measured by ELISA in the initiation cohort and by RIA in the withdrawal cohort prior to metreleptin initiation. 
Table 2. Diet and body composition off and on metreleptin treatment

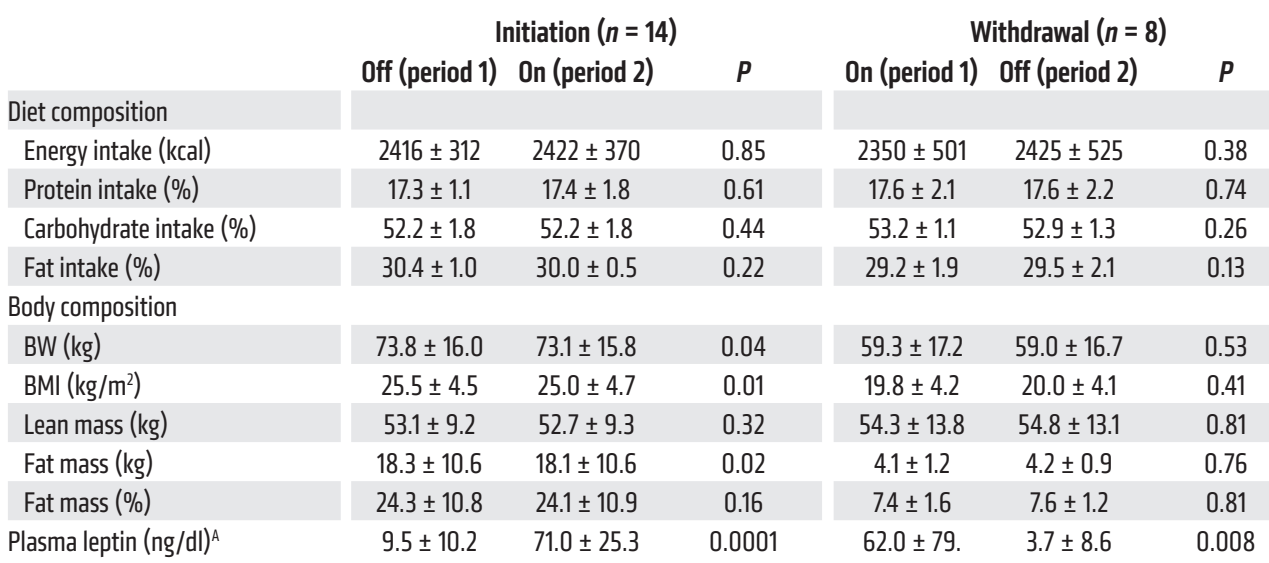

Data represent the mean $\pm \mathrm{SD}$. ${ }^{\mathrm{A} T h e}$ plasma leptin assay measures both endogenous leptin and exogenous metreleptin.

change the endogenous rate of appearance $(\mathrm{Ra})$ of glycerol or palmitate (Figure 4).

Decreases in hepatic triglyceride content with short-term metreleptin therapy were independent of food intake in the initiation cohort. In the initiation cohort, we noted a reduction in liver fat from $21.8 \% \pm 10.9 \%$ at the end of period 1 before metreleptin to $18.7 \% \pm 12.5 \%(P=0.03)$ at the end of period 2 on metreleptin (Figure 4). No changes in liver fat occurred in the withdrawal cohort, independent of food intake. We found that shortterm metreleptin did not change extramyocellular (EMCL) or intramyocellular lipid (IMCL)

from $152 \pm 42 \mathrm{mg} / \mathrm{dl}$ at the end of period 1 before metreleptin treatment to $136 \pm 34 \mathrm{mg} / \mathrm{dl}(P=0.003)$ at the end of period 2 on metreleptin (Figure 3 ). In addition, we found that 24-hour urine glucose excretion decreased from $2.0(0.2,10.3) \mathrm{g} / 24 \mathrm{~h}$ at the end of period 1 before metreleptin to $1.2(0.2,7.2) \mathrm{g} / 24 \mathrm{~h}(P=0.049)$ at the end of period 2 on metreleptin (Table 3). Hemoglobin A1c (HbA1c) decreased from $8.7 \% \pm 2.0 \%$ at the end of period 1 before metreleptin to $8.0 \% \pm 1.3 \%(P=0.002)$ at the end of period 2 on metreleptin. However, because the initial HbA1c reflected glycemic control for the 3 months prior to the study, this change cannot be considered as being independent of food intake. Relative to hospital admission, when patients were on an ad libitum diet, the mean insulin dose in these patients decreased by $95 \pm 126$ units per day at the end of period 2 on metreleptin $(P=0.04)$; however, there was no significant change in insulin dose or insulin secretion (measured as fasting C-peptide) independent of food intake. Fasting glucose, HbA1c, C-peptide, and urine glucose excretion did not change in the withdrawal cohort.

Short-term metreleptin therapy decreased triglycerides and total cholesterol, independent of food intake, in the initiation cohort, but did not change HDL-C, free fatty acids, or LDL-C. In the initiation cohort, triglycerides decreased from 556 [224, 1,144] (geometric mean [25th, 75th percentiles]) $\mathrm{mg} / \mathrm{dl}$ at the end of period 1 before metreleptin to $335[162,611] \mathrm{mg} / \mathrm{dl}$ at the end of period 2 on metreleptin $(P=0.01)$ (Figure 4$)$. Total cholesterol also decreased from $241 \pm 116 \mathrm{mg} / \mathrm{dl}$ at the end of period 1 to $171 \pm 48 \mathrm{mg} / \mathrm{dl}$ at the end of period $2(P=0.002)$ (Table 3$)$. In the withdrawal cohort, triglycerides and total cholesterol did not change. The magnitude of the decrease in total cholesterol in the on- versus off-metreleptin condition was greater in the leptin initiation cohort. Free fatty acids (FFA), HDL-C, and LDL-C did not change in either the initiation cohort or the withdrawal cohort (Table 3).

Lipolysis did not change with short-term metreleptin therapy, independent of food intake. We quantified lipolysis by infusing $\mathrm{D}_{5}$-glycerol and ${ }^{13} \mathrm{C}_{16}$-palmitate to measure turnover through isotope dilution studies. In the initiation and withdrawal cohorts, we found that shortterm metreleptin treatment with food intake held constant did not content, independent of food intake, in either the initiation or withdrawal cohort (Table 3).

Decreases in total and resting energy expenditure with short-term metreleptin therapy were independent of food intake in the initiation cohort. In the initiation cohort, we observed that total energy expenditure (TEE) decreased from 2,463 $\pm 362 \mathrm{kcal} /$ day at the end of period 1 before metreleptin to $2,319 \pm 400 \mathrm{kcal} /$ day at the end of period 2 on metreleptin $(P=0.001)$. Resting energy expenditure (REE) also decreased in this cohort from 1,855 $\pm 289 \mathrm{kcal} /$ day to $1,736 \pm 308 \mathrm{kcal} /$ day $(P=0.01)$; this change was no longer statistically significant after adjusting for changes in lean and fat mass. Non-resting EE (total minus resting) did not change in the initiation cohort. We found that TEE, REE, and non-resting EE did not change in the withdrawal cohort, independent of food intake.

\section{Long-term effects of metreleptin while on an ad libitum diet}

To study the long-term effects of metreleptin, the initiation cohort returned for a follow-up visit after $6.8 \pm 1.0$ months of metreleptin therapy. At this visit and during the previous 6 months, patients were on an ad libitum diet, thus any observed effects of metreleptin were not independent of food intake.

Long-term metreleptin therapy decreased BW, fat mass, lean mass, and body fat percentage in the initiation cohort. At the 6-month follow-up visit for the initiation cohort on an ad libitum diet, BW decreased from $73.8 \pm 16.0 \mathrm{~kg}$ before metreleptin to $70.8 \pm 16.8 \mathrm{~kg}$ $(P=0.005)$, fat mass decreased from $18.3 \pm 10.6 \mathrm{~kg}$ to $15.5 \pm 10.0$ $\mathrm{kg}(P=0.028)$, lean mass decreased from $53.1 \pm 9.2 \mathrm{~kg}$ to $51.5 \pm 9.4$ $\mathrm{kg}(P=0.002)$, and body fat percentage decreased from $24.3 \% \pm$ $10.8 \%$ to $21.3 \% \pm 10.6 \%(P=0.02)$.

Long-term metreleptin therapy maintained improvements in peripheral and hepatic insulin sensitivity. At the 6-month follow-up visit for the initiation cohort on an ad libitum diet, peripheral insulin sensitivity improvement was maintained at $8.0 \pm 4.0 \mathrm{mg} / \mathrm{kg}_{\mathrm{FFM}} / \mathrm{min}(P=0.01 \mathrm{vs}$. period 1$)$. We observed no further increase in peripheral insulin sensitivity at the 6-month follow-up visit relative to that in period 2 in the unadjusted analysis $(P=0.09$, Figure 3$)$, although this difference was sig- 
A

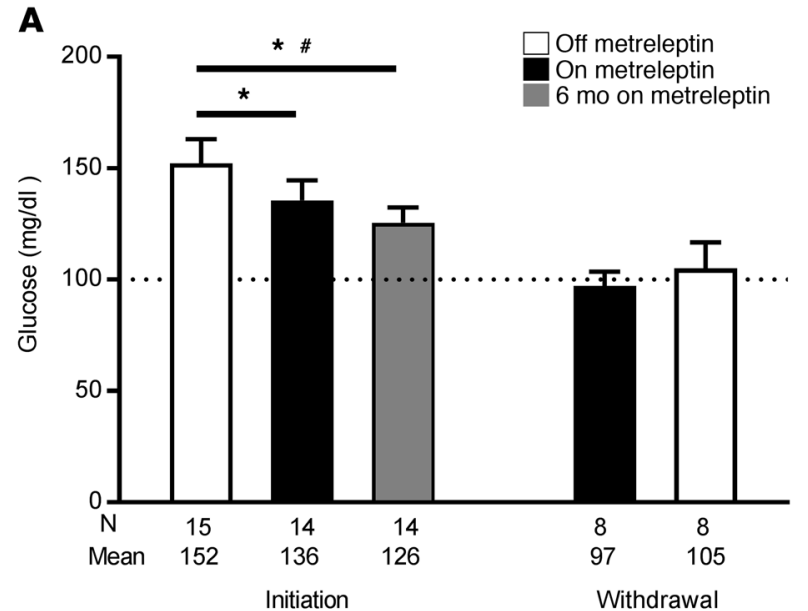

C

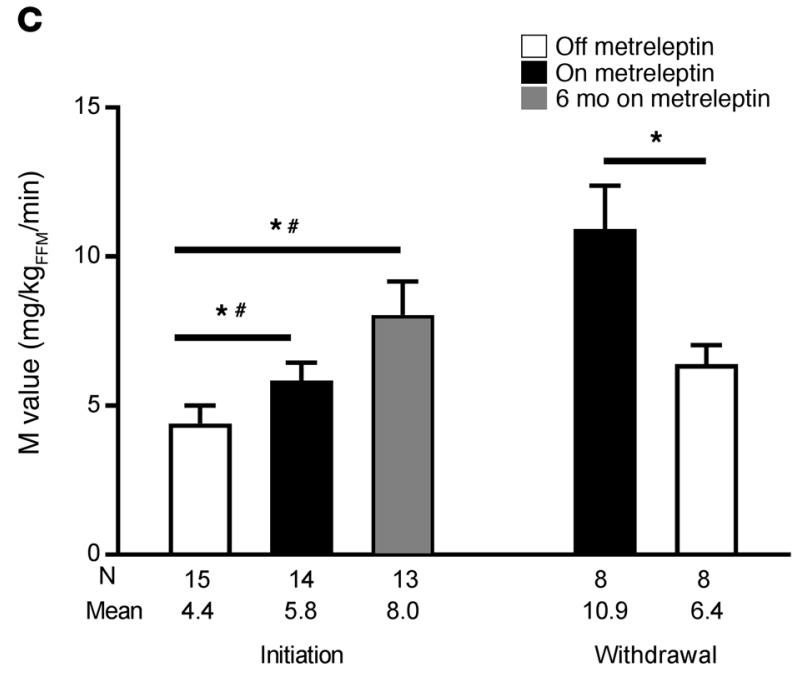

B

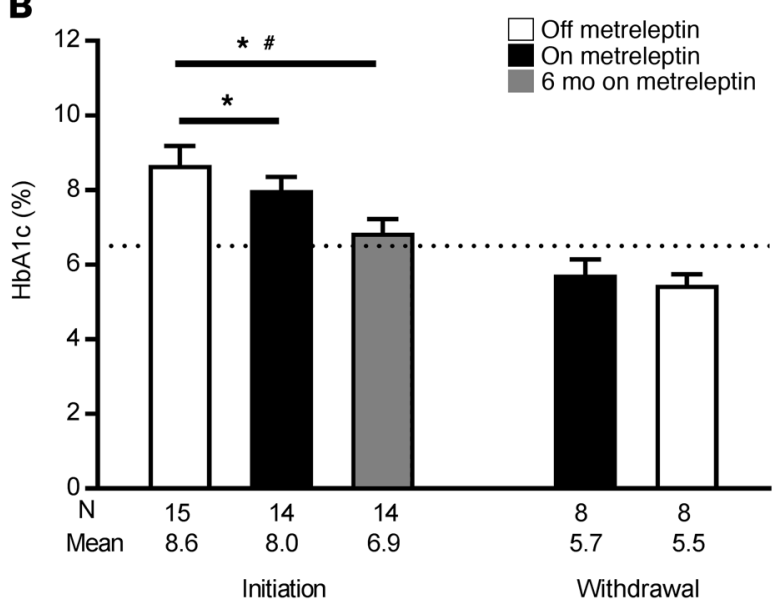

D

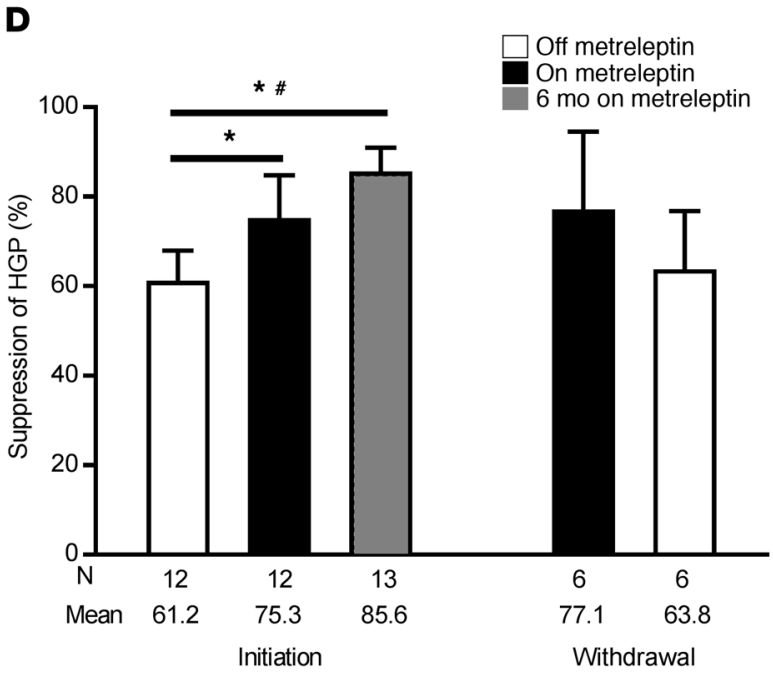

Figure 3. Improvements in glucose control and insulin sensitivity were independent of food intake in humans with lipodystrophy while on metreleptin. (A) Fasting glucose levels in leptin initiation and leptin withdrawal subjects while off (white bars), on (black bars), and after 6 months on (gray bars) metreleptin. The dotted line indicates of the upper limit of normal $(100 \mathrm{mg} / \mathrm{dl})$. (B) HbA1c values. The dotted gray line indicates the threshold for the diagnosis of diabetes (6.5\%). (C) Whole-body insulin sensitivity reflected by the M value (hyperinsulinemic-euglycemic clamp). (D) Insulin-mediated suppression of HGP as an indicator of hepatic insulin sensitivity. Data shown represent the mean \pm SEM. The study was powered to detect differences between the off- versus on-leptin state (black versus white bars) during constant food intake. ${ }^{*} P<0.05$, by 2 -tailed $t$ test or Wilcoxon matched pairs, signed-rank test between each pair of time points, based on data distribution. ${ }^{P} P<0.05$, by linear mixed model for all 3 time points, with post-hoc pairwise Bonferroni correction in the leptin initiation cohort. N, number.

nificant after adjustment for covariates $(P=0.048$, Supplemental Table 1). Likewise, we found that hepatic insulin sensitivity improvement was maintained at the 6-month follow up visit, at $86 \% \pm 18 \%$ suppression of HGP ( $P=0.02$ vs. period 1$)$, but there was no further increase in hepatic insulin sensitivity relative to that of period 2 (Figure 3).

Changes in hepatic triglyceride content significantly predicted long-term changes in peripheral insulin sensitivity with metreleptin treatment (period 1 versus 6-month follow-up, and period 2 versus 6-month follow-up) (Supplemental Tables 2 and 3). Hepatic triglyceride content also significantly predicted changes in hepatic insulin sensitivity from period 2 to the 6-month follow-up point (Supplemental Tables 2 and 3). Changes in both peripheral and hepatic insulin sensitivity (period 1 vs. 6-month follow-up) were no longer statistically significant after adjustment for changes in hepatic triglyceride content (Supplemental Table 3). Intramyocellular triglyceride content was not a significant predictor of long-term change in peripheral or hepatic insulin sensitivity in most models (Supplemental Tables 2 and 4 ).

Long-term metreleptin therapy maintained improvements in fasting glucose and HbA1c. At the 6-month follow-up for the initiation cohort on an ad libitum diet, the reduction in fasting glucose was maintained at $126 \pm 26 \mathrm{mg} / \mathrm{dl}$ ( $P=0.02$ vs. period 1$)$, and the reduction in HbA1c was also maintained at $6.9 \pm 1.4 \%(P=0.01$ vs. period 1$)$, but there were no further decreases relative to period 2 (Figure 3). We observed reductions in glycemia in the initiation cohort, despite decreases in insulin doses in 9 of 10 insulin-treated subjects. Relative to hospital admission, the mean insulin dose in these patients decreased by $112 \pm 109$ units per day (a $50 \%$ reduction) at the 6-month follow-up $(P=0.01)$. Two subjects discontinued insulin use by their six-month follow-up. The mean number of diabetes med- 
Table 3. Metabolic characteristics off and on metreleptin treatment

\begin{tabular}{|c|c|c|c|c|c|}
\hline & \multicolumn{3}{|c|}{ Initiation $(n=14)$} & \multicolumn{2}{|c|}{ Withdrawal $(n=8)$} \\
\hline & Off (period 1) & On (period 2) & On (6 months) & On (period 1) & Off (period 2) \\
\hline \multicolumn{6}{|l|}{ Glycemic parameters } \\
\hline Fasting glucose (mg/dl) & $152 \pm 42$ & $136 \pm 34^{A}$ & $126 \pm 26^{B}$ & $97 \pm 18$ & $105 \pm 33$ \\
\hline Fasting C-peptide (ng/ml) & $4.0 \pm 1.6$ & $4.2 \pm 1.9$ & $3.4 \pm 1.9$ & $3.5 \pm 1.4$ & $5.2 \pm 2.2$ \\
\hline Urinary glucose excretion (g/24 h) & $2.0[0.2,10.3]$ & $1.2[0.2,7.2]^{\mathrm{A}}$ & $0.4[0.1,0.6]$ & $0.2[0.1,0.7]$ & $0.3[0.1,2.4]$ \\
\hline Total cholesterol (mg/dl) & $241 \pm 116$ & $171 \pm 48^{A}$ & $171 \pm 58^{B}$ & $129 \pm 32$ & $123 \pm 29$ \\
\hline LDL-C (mg/dl) & $87 \pm 34$ & $78 \pm 33$ & $73 \pm 32$ & $68 \pm 27$ & $54 \pm 24$ \\
\hline HDL-C (mg/dl) & $27 \pm 5$ & $25 \pm 5$ & $28 \pm 5$ & $32 \pm 7$ & $29 \pm 8$ \\
\hline $\mathrm{FFA}(\mathrm{mEq} / \mathrm{l})$ & $0.43 \pm 0.17$ & $0.42 \pm 0.18$ & $0.41 \pm 0.10$ & $0.20 \pm 0.09$ & $0.23 \pm 0.06$ \\
\hline
\end{tabular}

Data represent the mean \pm SD or the geometric mean [25th, 75th percentiles], based on the distribution of the data. ${ }^{A}$ Significant difference between period

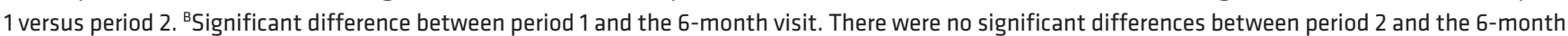
visit in the initiation cohort.

ications (insulin plus other agents) did not change after 6 months. We noted no significant changes in C-peptide during the study.

Long-term metreleptin therapy maintained improvements in triglycerides and total cholesterol. At the 6-month follow-up for the initiation cohort on an ad libitum diet, the reduction in triglycerides was maintained at $304[122,547](P=0.24$ vs. period 1) (Figure 4), and the reduction in total cholesterol was maintained at $129 \pm 32$ $(P=0.02$ vs. period 1$)$, but we detected no further decreases relative to period 2. FFA, HDL-C, and LDL-C did not change during the study (Table 3). The mean number of lipid-lowering medications did not change during the study.

Long-term metreleptin therapy decreased glycerol and palmitate turnover in the initiation cohort. At 6-month follow-up for the initiation cohort on an ad libitum diet, palmitate turnover decreased by $30 \%$ from $3.2 \pm 1.3 \mu \mathrm{mol} / \mathrm{kg}$ lean body mass $(\mathrm{LBM})$ per minute prior to metreleptin treatment in period 1 to $2.2 \pm 0.7 \mu \mathrm{mol} / \mathrm{kg}_{\mathrm{LBM}} / \mathrm{min}(P=$ $0.02)$, and glycerol turnover decreased by $35 \%$ from $4.5 \pm 2.3 \mu \mathrm{mol} /$ $\mathrm{kg}_{\mathrm{LBM}} / \mathrm{min}$ prior to metreleptin in period 1 to $2.9 \pm 0.7 \mu \mathrm{mol} / \mathrm{kg}_{\mathrm{LBM}} /$ $\min (P=0.02)$, indicating a decrease in lipolysis (Figure 4$)$.

Long-term metreleptin therapy maintained the reduction in liver fat and reduced alanine transaminase and aspartate aminotransferase. At the 6-month follow-up for the initiation cohort on an ad libitum diet, the reduction in liver fat was maintained at $13.6 \% \pm 9.7 \%(P=$ 0.006 vs. period 1$)$, but we observed no further improvement relative to that of period 2 (Figure 4). Alanine transaminase (ALT) and aspartate aminotransferase (AST) were measured upon study entry (prior to the controlled diet) but not at the end of period 1, thus any changes observed were not independent of food intake. The mean ALT was elevated at study entry (before metreleptin treatment), at $64 \pm 54 \mathrm{U} / 1$ (normal $\leq 41$ in males over 18 years, $\leq 33$ in females over 18 years, $\leq 30$ in children), decreased nonsignificantly to $43 \pm$ $23 \mathrm{U} / 1$ after 2 weeks, and decreased significantly to $26 \pm 13 \mathrm{U} / \mathrm{l}$ after 6 months of metreleptin treatment relative to levels at study entry $(P=0.004)$. The mean AST was borderline elevated at study entry, at $39 \pm 25 \mathrm{U} / 1$ (normal is $\leq 40 \mathrm{U} / 1$ in males over 18 years, $\leq 32 \mathrm{U} / 1$ in females over 18 years, and $\leq 40 \mathrm{U} / \mathrm{l}$ in children), decreased significantly to $30 \pm 19 \mathrm{U} / \mathrm{l}$ after 2 weeks, and further decreased to $22 \pm$
$7 \mathrm{U} / \mathrm{l}$ after 6 months of metreleptin treatment $(P=0.03$ relative to study entry; $P=0.04$ relative to 2 weeks on metreleptin).

Long-term metreleptin therapy did not change IMCL and had variable effects on EMCL. We found that IMCL did not change in any muscle group after 6 months of metreleptin treatment but that EMCL decreased in the lateral vastus and tibialis anterior muscles and increased in the soleus muscle (Table 4).

Long-term metreleptin therapy maintained the reduction in TEE and REE. At the 6-month follow-up for the initiation cohort on an ad libitum diet, the reductions in TEE and REE were maintained at $2,296 \pm 372 \mathrm{kcal} /$ day and $1,731 \pm 236 \mathrm{kcal} /$ day, respectively ( $P=0.02$ vs. period 1 for both), but we observed no further change relative to period 2 .

Adverse events. The following nonserious adverse events occurred in 1 subject each in the initiation cohort during long-term metreleptin treatment and were considered to be at least possibly related to the treatment: decreased appetite, weight loss, hair loss, hypoglycemia (in a subject treated with insulin), injection site reaction, and menorrhagia. Serious adverse events that were not considered to be related to treatment were: abdominal pain of unknown etiology $(n=1)$, angioedema secondary to angiotensinconverting enzyme inhibitor use $(n=1)$, and anemia secondary to menorrhagia ( 2 events in 1 subject).

\section{Discussion}

In patients with lipodystrophy, metreleptin therapy ameliorates metabolic abnormalities by reducing food intake $(3,12,13)$, improving insulin resistance and diabetes $(4,13-15)$, and reducing ectopic lipid (7). These improvements in glucose and lipid metabolism are likely due in part to the reduction in food intake, but the clinical effects of metreleptin that are independent of changes in food intake have been poorly explored in humans. A single patient with acquired, generalized lipodystrophy was studied while taking metreleptin and during metreleptin withdrawal, with constant energy intake (13). Upon metreleptin withdrawal, this patient experienced no changes in blood glucose but had a rise in serum insulin and triglyceride levels within 1 week (13). Although based 
A

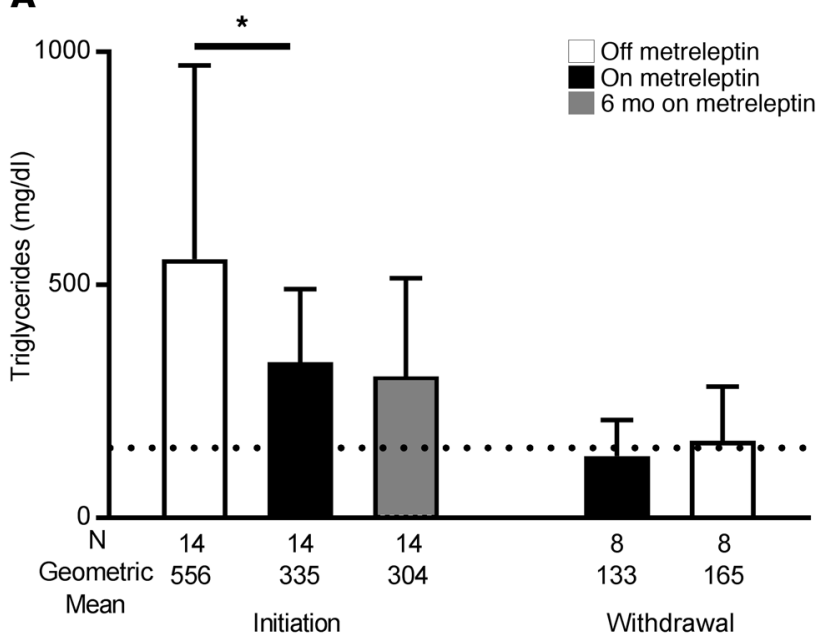

C

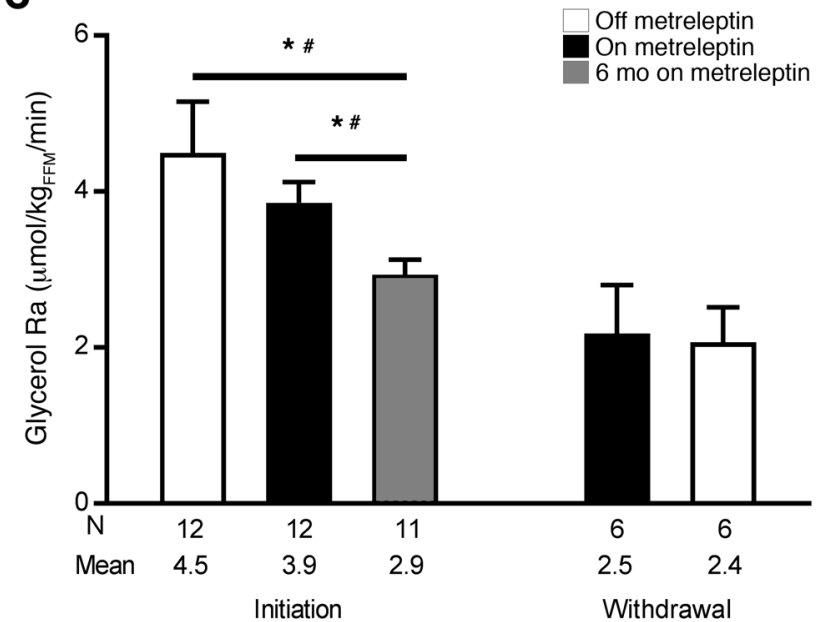

B



D

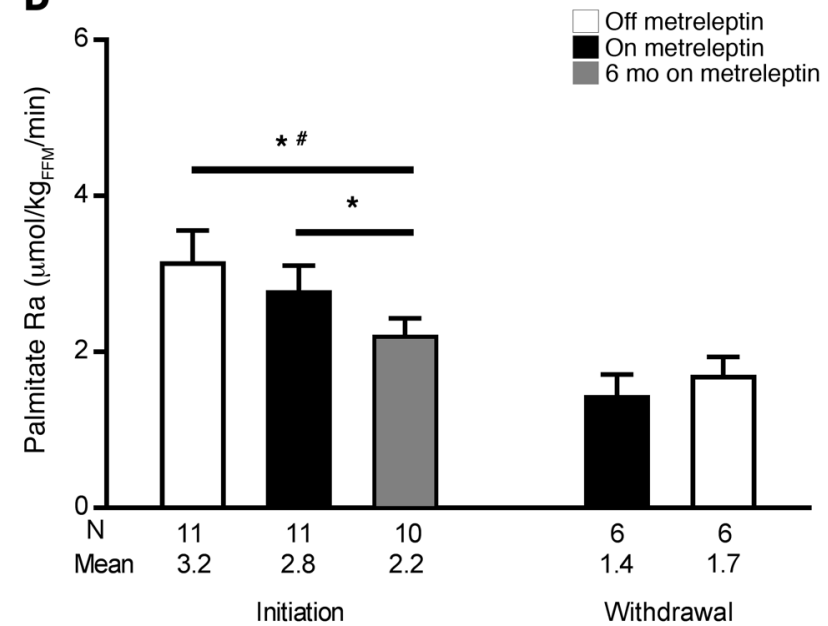

Figure 4. Decreases in triglycerides and liver fat were independent of food intake in humans with lipodystrophy while on metreleptin. (A) Triglyceride levels in leptin initiation subjects and leptin withdrawal subjects while off, on, or after 6 months on metreleptin. The dotted line indicates the upper limit of normal (150 mg/dl). (B) Liver fat percentage measured by MRS. The dotted line indicates the upper limit of normal (5\%). (C) Glycerol Ra in plasma. (D) Palmitate Ra in plasma. Data shown represent the mean \pm SEM or the geometric mean $\pm 95 \% \mathrm{Cl}$ (triglycerides). The study was powered to detect differences between the off- versus on-leptin state (black versus white bars) during constant food intake. ${ }^{*} P<0.05$, by 2 -tailed $t$ test or Wilcoxon matched pairs, signed-rank test between each pair of time points, based on data distribution. ${ }^{P}<0.05$, by linear mixed model for all 3 time points, with post-hoc pairwise Bonferroni correction in the leptin initiation cohort.

on a single subject, these data suggested that leptin affects both insulin resistance and lipid metabolism and that these effects are independent of energy intake in humans. Our study demonstrates that metreleptin has food-intake-independent effects in humans with lipodystrophy, increasing peripheral and hepatic insulin sensitivity, and decreasing fasting glucose, triglycerides, total cholesterol, and liver fat percentage. As expected, we found that the magnitude of the effects of metreleptin independent of food intake over 2 weeks was smaller than the maximal effects of longterm metreleptin treatment during ad libitum food intake shown in previous studies (Figure 5) $(4,7,15)$.

Because leptin reduces appetite (13), its effects independent of food intake cannot be studied in a free-living environment with ad libitum access to food. In this study, the tightly controlled nature of a metabolic ward permitted meticulous control of dietary intake, and our data confirmed that the participants' food intake was suc- cessfully held constant for nineteen days. It is likely that many of the biological effects of leptin require more than 2 weeks of treatment initiation or withdrawal to show maximal changes, and therefore our study may underestimate the biological effects of leptin that are independent of food intake. Although it would have been informative to continue the study for a longer duration, nineteen days was the practical limit during which we could keep patients hospitalized and on a controlled diet.

The most consistent effect of metreleptin independent of food intake was an improvement in peripheral insulin sensitivity, which was $32 \%$ greater in the initiation cohort and $41 \%$ greater in the withdrawal cohort during the metreleptin treatment periods. Hepatic insulin sensitivity was higher during metreleptin treatment in the initiation cohort only. Our human data are consistent with previous findings in rodents, which showed that leptin improved peripheral and hepatic insulin sensitivity by $12 \%$ to $33 \%$ 


\begin{tabular}{|l|c|c|}
\hline & $\begin{array}{c}\text { Effects of leptin } \\
\text { independent of } \\
\text { food intake }\end{array}$ & $\begin{array}{c}\text { Maximal effects } \\
\text { of leptin of } \\
\text { food intake }\end{array}$ \\
\hline $\begin{array}{l}\text { Peripheral insulin } \\
\text { sensitivity }\end{array}$ & $\uparrow$ & \\
\hline $\begin{array}{l}\text { Hepatic insulin } \\
\text { sensitivity }\end{array}$ & $\uparrow$ & $\downarrow$ \\
\hline Blood glucose & $\downarrow$ & $\downarrow$ \\
\hline Lipolysis & $\leftrightarrow$ & $\downarrow$ \\
\hline $\begin{array}{l}\text { Plasma } \\
\text { triglycerides }\end{array}$ & $\downarrow$ & $\downarrow$ \\
\hline $\begin{array}{l}\text { Hepatic } \\
\text { triglycerides }\end{array}$ & $\downarrow$ & $\downarrow$ \\
\hline $\begin{array}{l}\text { Intramyocellular } \\
\text { lipid }\end{array}$ & $\leftrightarrow$ & $\downarrow$ \\
\hline
\end{tabular}

Figure 5. Effects of leptin independent of food intake in patients with lipodystrophy versus the maximal effects of leptin during ad libitum food intake. The current study demonstrates the effects of leptin replacement with metreleptin, with food intake held constant over a 2 -week period. These effects were smaller in magnitude than the maximal effects of metreleptin demonstrated in long-term studies with ad libitum food intake. Up arrow indicates increase, down arrow indicates decrease, double-headed left/right arrow indicates no change. The size of the arrow indicates the relative size of the effect.

and $32 \%$ to $41 \%$, respectively, and that these improvements were independent of food intake $(16,17)$. Consistent with the improvements in insulin sensitivity, we found that 2 weeks of metreleptin improved fasting glucose by $11 \%$. Likewise, an approximately $42 \%$ to $53 \%$ reduction in fasting glucose has been observed in pair-fed, leptin-deficient rodent studies $(10,11)$.

Given prior studies in humans $(7,18)$, we hypothesized that improved insulin sensitivity with metreleptin would be due to reductions in ectopic triglycerides in liver and myocytes. However, only reductions in hepatic triglycerides were observed. Numerous studies have demonstrated an association between hepatic triglyceride content and peripheral insulin resistance, however, the direction of causality in this relationship is unclear (19-22). Although it is possible that lipid-laden hepatocytes secrete cytokines or other substances that increase muscle insulin resistance, it is also possible that skeletal muscle or adipose tissue insulin resistance leads to hepatic triglyceride accumulation through mechanisms such as increased FFA delivery from adipose tissue to liver or increased de novo lipogenesis stimulated by hyperinsulinemia. In rodents, a liver-targeted mitochondrial uncoupling agent led to decreases in both hepatic and peripheral insulin resistance, supporting the notion of a causal relationship between hepatic triglycerides and peripheral insulin resistance (23). Multivariate analyses in the current study also support a stronger role for intrahepatic triglycerides (versus intramyocellular triglycerides) in mediating both hepatic and peripheral insulin resistance, although we cannot prove a causal relationship. Changes in hepatic tri- glyceride content, but not intramyocellular triglyceride content, significantly predicted changes in both peripheral and hepatic insulin sensitivity, and changes in insulin sensitivity were no longer statistically significant after adjustment for changes in hepatic triglycerides. This suggests that reductions in hepatic triglyceride content with metreleptin may have mediated the improvements in insulin sensitivity.

Although patients who initiated metreleptin lost a small amount of weight and fat mass during metreleptin treatment with constant food intake, these changes in body composition did not predict changes in insulin sensitivity, and thus the small reductions in weight and body fat observed in the metreleptin initiation cohort were not likely to have contributed to improved insulin sensitivity. An unexpected finding was the decrease in TEE and REE in the metreleptin initiation cohort during the period of constant food intake. Limited data on patients with congenital leptin deficiency or weight loss have suggested that metreleptin either does not change energy expenditure (24) or increases nonresting $\operatorname{EE}(25,26)$. The biology underlying the reduction in REE in this study remains to be determined but might include decreased urinary glucose loss, decreased energetic cost of hepatic glucose production $(27,28)$, decreased patient movement during the measurement of energy expenditure after repeated testing (29), and the fact that the subjects were in a slightly negative energy balance. Regardless of the reason for decreased energy expenditure, it is clear that there was no increase in energy expenditure with metreleptin that contributed to weight loss or improved insulin sensitivity.

Our study shows that there are food-intake-independent effects of metreleptin on lipid metabolism, with a reduction in circulating and hepatic triglycerides and total cholesterol in humans with lipodystrophy. Although rodent studies have not demonstrated clinically relevant changes in lipids independent of food intake, mechanistic studies in rodents have suggested that these effects may be mediated by increased expression of enzymes and transcription factors involved in fatty acid oxidation (e.g., mitochondrial and peroxisomal acyl-coenzyme A oxidase, peroxisomal proliferator-activated receptor $\alpha$ ) and decreased expression of those regulating fatty acid synthesis (e.g., stearoyl-CoA desaturase-1) (30-32).

We found that metreleptin treatment for 6 months while on an ad libitum diet decreased both glycerol and palmitate turnover in subjects with lipodystrophy, indicating a reduction in lipolysis. This reinforces data from a prior study involving 3 subjects with lipodystrophy, in whom 3 to 5 months of metreleptin treatment nonsignificantly decreased glycerol turnover (7). In contrast, in vitro and in vivo rodent studies have shown that leptin treatment reduces muscle, liver, and adipose triglyceride content by increasing lipolysis and fatty acid oxidation (33-39). These lipolytic effects of leptin have been shown in obese rodents with mutations in the leptin gene or the leptin receptor, but not in rodents with lipodystrophy, suggesting that the observed lipolytic effects of leptin require normal adipose depots. Contrary to the findings in obese rodent models, long-term metreleptin had antilipolytic effects in subjects with lipodystrophy. Although humans with lipodystrophy have a paucity of adipose tissue, these subjects are known to have elevated rates of lipolysis compared with gender-, age-, and BMI-matched controls prior to metreleptin therapy, presumably reflecting greater lipolysis in their residual fat 
mass (7). The effects of long-term metreleptin on the suppression of lipolysis are presumably secondary to improved insulin sensitivity and, hence, increased insulin-mediated suppression of lipolysis. Given the hierarchy of physiologic responses to insulin, with suppression of lipolysis being the most sensitive, followed by suppression of hepatic glucose production, followed by glucose uptake in muscle, it is somewhat surprising that short-term metreleptin treatment suppressed hepatic glucose production and increased muscle glucose uptake, but did not decrease lipolysis. We speculate that the null effects of short-term metreleptin on lipolysis may be due to opposing direct lipolytic effects of leptin versus the indirect suppression of lipolysis mediated by improved insulin sensitivity.

A limitation of our study was the small number of participants, but lipodystrophy is a rare disorder. We had limited success in demonstrating the biological effects of metreleptin withdrawal independent of food intake. Other than effects on peripheral insulin sensitivity, the withdrawal cohort did not experience the food-intake-independent effects of metreleptin therapy that we observed in the initiation cohort. This may have been due to the small sample size, as there were few statistical differences for metabolic changes in the on- versus off-metreleptin periods between the withdrawal and initiation cohorts. The lack of changes in the withdrawal cohort may also be due to 2 biological factors. First, the withdrawal cohort had an average of $7.7 \pm 4.7$ (range, 0.9-14.5) years of prior metreleptin treatment, resulting in euglycemia and normal triglycerides, despite their lipodystrophy diagnosis. Second, 2 weeks of metreleptin withdrawal may have been insufficient to detect metabolic changes in the withdrawal cohort. By contrast, the initiation cohort had no exposure to metreleptin and worse metabolic profiles at baseline, allowing for metabolic changes that were of greater magnitude. The 2 groups also differed in the types of lipodystrophy. In the withdrawal cohort, all subjects had generalized lipodystrophy, and in the initiation cohort, most subjects had partial lipodystrophy. This difference is not a likely explanation for the lack of effects in the withdrawal cohort, because we would have expected greater effects in subjects with generalized lipodystrophy who had lower endogenous leptin levels, which we did not observe.

By using lipodystrophy as a model for leptin deficiency and replacement, we have successfully demonstrated that metreleptin therapy has food-intake-independent effects on glucose and lipid metabolism in humans. In addition to serving as a model for leptin deficiency, lipodystrophy is also a more severe form of the obesityassociated metabolic syndrome. Although metreleptin treatment has biological effects in states of chronic hypoleptinemia, it has little effect on appetite, BW, or hormonal axes in leptinreplete subjects undergoing either mild, ongoing caloric restriction or acute, severe energy restriction (72-hour fast), despite the fact that caloric restriction can acutely decrease leptin levels (40-43). This study provides evidence for food-intakeindependent effects of metreleptin in leptin-deficient humans, but the effects of leptin independent of food intake have yet to be explored in leptin-sufficient human models such as that of obesity-associated metabolic syndrome.

\section{Methods}

Study subjects. This was a nonrandomized, crossover group study involving 2 groups (leptin initiation and leptin withdrawal) of patients with lipodystrophy, aged 14 to 70 years. Participants were recruited by referral from November 2012 to January 2017. The subjects in the leptin initiation group had no prior exposure to exogenous metreleptin, and the subjects in the leptin withdrawal group had taken a stable dose of exogenous metreleptin for a minimum of 4 months prior to study participation. Metreleptin was provided by Aegerion Pharmaceuticals. The flow chart of the study participants in each cohort is shown in Figure 1. Of the 25 patients enrolled, 15 were in the leptin initiation cohort, and 10 were in the leptin withdrawal cohort. In the leptin initiation cohort, 1 subject did not complete data collection for the shortterm study but continued the study drug and completed the long-term study, and another subject completed the short-term study but was excluded from analysis in the long-term study because of noncompliance with metreleptin therapy. In the leptin withdrawal cohort, 1 subject withdrew consent, and another subject was excluded from analysis because of recurrent hypoglycemia during the short-term study. Therefore, 14 subjects in the leptin initiation cohort and 8 subjects in the leptin withdrawal cohort were included in the final analysis.

Inclusion and exclusion criteria. Eligibility was based on a clinical diagnosis of lipodystrophy, age 14 years or older, and 1 or more metabolic abnormalities including diabetes mellitus defined by the 2007 American Diabetes Association criteria, insulin resistance (fasting insulin $\geq 30 \mu \mathrm{IU} / \mathrm{ml}$ ), or hypertriglyceridemia (fasting triglyceride $>200 \mathrm{mg} / \mathrm{dl}$ ). The patients were also required to have low endogenous serum leptin levels, measured either at the NIH or at an outside laboratory prior to metreleptin treatment $(<8 \mathrm{ng} / \mathrm{ml}$ in males, $<12 \mathrm{ng} / \mathrm{ml}$ in females). Exclusion criteria included HIV-associated lipodystrophy, active inflammatory disease, or glucocorticoid use, and changes in diabetes or lipid-lowering medications within the past 6 weeks. Because of the risk of worsening metabolic status with metreleptin withdrawal, additional exclusion criteria were applied to the leptin withdrawal cohort and included age younger than 18 years, HbA1c of $9 \%$ or higher, serum triglycerides above $800 \mathrm{mg} /$ $\mathrm{dl}$, more than 1 lifetime episode of acute pancreatitis or 1 or more episodes of pancreatitis while on metreleptin, lipase greater than 
the upper limit of normal at study entry, or known presence of neutralizing antibodies against leptin.

Study design. The study design is shown in Figure 2. The initiation subjects were studied for the first 5 days before metreleptin treatment (period 1) and then treated with metreleptin $(5 \mathrm{mg}$ s.c. every 12 hours) for the next 14 days (period 2). The withdrawal subjects were studied for the first 5 days on their home dose of metreleptin (period 1) and then withdrawn from metreleptin for the next 14 days (period 2). The study subjects and investigators were not blinded to the intervention. All subjects were hospitalized in the metabolic unit of the NIH Clinical Center and consumed a controlled diet provided by the metabolic kitchen. The study diet was controlled for macronutrient content $(20 \% \pm 5 \%$ protein, $25 \% \pm 5 \%$ fat, $55 \% \pm 5 \%$ carbohydrate). Research dietitians used the Mifflin-St. Jeor equations for males with an activity factor of 1.5 to estimate total caloric requirements (for both male and female participants). Food intake (total kilocalories and macronutrient content) was adjusted for BW fluctuations to ensure eucaloric feeding during period 1 , and then the energy was clamped for period 2 in order to assess the effects of leptin independent of energy intake. The subjects were instructed on the importance of eating $100 \%$ of the food given and not consuming any additional food. However, to determine possible deviations from the study diet, any uneaten food was weighed, and the uneaten kilocalories were recorded. At the end of period 2, metreleptin was restarted in subjects in the withdrawal cohort at their previous doses. Patients in the initiation cohort continued self-administered metreleptin treatment after discharge and underwent follow-up evaluation after 6 months of treatment while on an ad libitum diet. For patients in the initiation cohort with partial lipodystrophy, metreleptin was continued at a dose of $5 \mathrm{mg}$ every 12 hours. For patients in the initiation cohort with generalized lipodystrophy, the metreleptin dose was lowered at the end of period 2 to prevent excessive weight loss during the 6-month follow-up period.

Apart from insulin and sulfonylureas, the subjects continued their preadmission medications throughout the study, including oral hypoglycemic agents, lipid-lowering medications, and other medications either related or unrelated to lipodystrophy and its complications. The initiation subjects taking insulin or sulfonylureas were at risk of hypoglycemia due to improved insulin sensitivity after metreleptin. None of the withdrawal subjects was taking insulin. For subjects with diabetes, glucose monitoring was performed prior to meals and at bedtime. Because of the risk of hypoglycemia, insulin and sulfonylurea doses were reduced as needed to minimize hypoglycemia.

Primary outcomes. The aim of this study was to determine the energy-intake-independent effects of leptin on glucose and lipid metabolism in lipodystrophic subjects. The prespecified primary outcome for glucose metabolism was total body insulin sensitivity (measured as the glucose disposal rate during a hyperinsulinemiceuglycemic clamp), and for lipid metabolism, the prespecified primary outcome was the rate of lipolysis (measured using glycerol stable isotope tracers). For leptin initiation and withdrawal cohorts, clinical values were collected at study entry, at the end of period 1 , and at the end of period 2 (Figure 2). Additional clinical values were obtained at the 6-month follow-up visit for subjects in the leptin initiation cohort who were on an libitum diet.

Additional outcomes included serum leptin levels, anthropometric parameters (BMI and body fat percentage), glycemic and lipid variables (fasting glucose, fasting insulin, fasting C-peptide, HbA1c, lipids, urinary glucose excretion, number of antidiabetic and lipid-lowering medications, insulin use and average daily insulin dose among insulin users), hepatic insulin sensitivity (measured as the suppression of endogenous glucose production during a hyperinsulinemic-euglycemic clamp), rates of lipolysis and fatty acid turnover (measured using glycerol and palmitate stable isotope tracers), and lipid content in liver and skeletal muscles (measured using magnetic resonance spectroscopy [MRS]).

Metabolites and hormones. Blood samples were obtained following an 8- to 12-hour fast. Urine was collected over 24-hour periods. Glucose, insulin, C-peptide, HbA1c, total cholesterol, HDL-C, LDL-C, triglycerides, and urinary glucose excretion were analyzed using standard techniques of the NIH Clinical Center laboratory. In the withdrawal cohort, endogenous leptin in fasting serum samples was measured prior to metreleptin initiation by RIA (MilliporeSigma). The intra- and inter-assay coefficients of variation were $9.3 \%$ and $9.6 \%$, respectively. Of note, these samples for the measurement of endogenous leptin were collected immediately prior to metreleptin initiation, 0.9-14.5 years prior to participation in the current study, under other IRB-approved protocols. In both cohorts, leptin was also measured by ELISA (MilliporeSigma) in fasting EDTA plasma samples at the end of periods 1 and 2, and again after 6 months of metreleptin treatment in the initiation cohort. The intra- and inter-assay coefficients of variation were $3.9 \%$ and $4.8 \%$, respectively.

Body composition. A dual-energy x-ray absorptiometry (DXA) scan was obtained to measure fat and lean body mass at the end of period 1 and period 2 for both cohorts and during the 6-month follow-up for the initiation cohort only (iDXA, GE Healthcare).

Energy expenditure. Energy expenditure was measured at the end of period 1 and period 2 for both cohorts and during the 6-month follow-up for the initiation cohort only. REE was measured using indirect calorimetry with a hood calorimeter (TrueOne 2400, ParvoMedics) upon awakening after a minimum 8-hour fast, with the patient in a resting supine position. Twenty-four-hour TEE was measured using a whole-room, indirect calorimeter (metabolic chamber) (44). Periods of exercise during the 24-hour metabolic chamber stay were assessed using a microwave detection system; these periods were excluded from the TEE analysis, with data renormalized to a 24-hour period. Non-resting EE was calculated as the difference between TEE and REE.

$M R I$ and MRS. Hepatic triglyceride content was measured using MRS as previously described $(45,46)$. Intramyocellular and extramyocellular triglyceride content in the vastus lateralis, anterior tibialis, and soleus muscles was measured using MRS as previously described (46).

Tracer dilution and clamp studies. Following an overnight fast, stable isotope tracers were used to measure glucose, glycerol, and palmitate turnover by the tracer dilution method. At 0500 hours, 1 catheter was inserted into the forearm vein to infuse stable isotopically labeled tracers. A second catheter was inserted into a vein in the contralateral hand or arm to obtain blood samples. A primed, continuous infusion of $\left[6,6-{ }^{2} \mathrm{H}_{2}\right]$ glucose (priming dose, $28 \mu \mathrm{mol} / \mathrm{kg}$ of BW; infusion rate, $0.4 \mu \mathrm{mol} / \mathrm{kg}$ of $\mathrm{BW} / \mathrm{min}$ for $180 \mathrm{~min}$ ) was used to measure basal endogenous production (Cambridge Isotope Laboratories). At 0700 hours, a primed, continuous infusion of $\left[{ }^{2} \mathrm{H}_{5}\right]$ glycerol (priming dose, $0.045 \mu \mathrm{mol} / \mathrm{kg}$ of BW; infusion rate, $0.18 \mu \mathrm{mol} / \mathrm{kg}$ of BW/min) and an unprimed infusion of $\left[\mathrm{U}^{-13} \mathrm{C}_{16}\right]$ palmitate (infusion rate, $0.006 \mu \mathrm{mol} / \mathrm{kg}$ of $\mathrm{BW} / \mathrm{min}$ ) were administered for 60 minutes to measure the rate of lipolysis (Cambridge Isotope Laboratories). 
At 0830 hours, a hyperinsulinemic-euglycemic clamp study was started. Regular human insulin was infused at a priming rate of $240 \mathrm{mU} / \mathrm{m}^{2} / \mathrm{min}$ for 8 minutes, followed by a continuous insulin infusion at $120 \mathrm{mU} / \mathrm{m}^{2} / \mathrm{min}$ for approximately 3 hours. $\left[6,6-{ }^{2} \mathrm{H}_{2}\right]$ glucose was infused at $25 \%$ of the baseline rate $(0.1 \mu \mathrm{mol} / \mathrm{kg} \mathrm{BW} /$ $\mathrm{min})$. Dextrose solution (20\%) enriched with $2.5 \%\left[6,6-{ }^{2} \mathrm{H}_{2}\right]$ glucose tracer was infused at a variable rate to maintain blood glucose at 100 $\pm 5 \mathrm{mg} / \mathrm{dl}$. Because of severe insulin resistance and hyperglycemia, 2 subjects maintained a steady-state glucose level of $132 \pm 1.3 \mathrm{mg} /$ $\mathrm{dl}$ at all visits. Blood samples $(0.5 \mathrm{ml})$ were obtained every 5 to 10 minutes for analysis of the whole-blood glucose concentration, measured by an automated glucose analyzer (Yellow Springs Instruments Co.). Blood samples for analysis of glucose, insulin, C-peptide, and $\left[6,6-{ }^{2} \mathrm{H}_{2}\right]$ glucose were collected every 10 minutes during steady state (the final 30 minutes of the study).

Liquid chromatography-mass spectrometry. Isotope enrichment was measured using a Waters Acquity UPLC and a Thermo Fisher Scientific Q-Exactive (high-resolution, accurate-mass). The separation was done on a Waters $\mathrm{BEH}$ Amide column $(1.7 \mu \mathrm{m}, 2.1 \times 100$ $\mathrm{mm}$ ) using solvent $\mathrm{A}\left(30 \%\right.$ acetonitrile $[\mathrm{ACN}], 70 \% \mathrm{H}_{2} \mathrm{O}, 0.1 \% \mathrm{NH}_{3}$ ) and solvent $\mathrm{B}\left(80 \% \mathrm{ACN}, 20 \% \mathrm{H}_{2} \mathrm{O}, 0.1 \% \mathrm{NH}_{3}\right)$. The Q-Exactive with HESI-II electrospray negative ion source used the targeted selected ion monitoring (SIM) mode at 70,000 resolution for palmitate, 70,000 resolution full scan for glycerol, and targeted SIM mode at 140,000 resolution for glucose. Each targeted SIM was triggered by an inclusion list of the naturally occurring molecule. Glucose was measured at $m / z 179.0556,\left[6,6-{ }^{2} \mathrm{H}_{2}\right]$ glucose at 181.0684 , glycerol at 91.0388, $\left[{ }^{2} \mathrm{H}_{5}\right]$ glycerol at 96.0700, palmitate at 255.2336, and $\left[\mathrm{U}-{ }^{13} \mathrm{C}\right]$ palmitate at 271.2874. Standards of 0-16.7 molar percent enrichment (MPE) of [6,6- $\left.{ }^{2} \mathrm{H}_{2}\right]$ glucose, 0-13.1 MPE $\left[{ }^{2} \mathrm{H}_{5}\right]$ glycerol, and 0-0.9 MPE $\left[\mathrm{U}-{ }^{13} \mathrm{C}\right]$ palmitate were calibrated with an $R^{2}$ of greater than $0.99(47)$.

Calculations. The Ra of glucose, glycerol, and palmitate per kilogram of lean body mass was calculated by measuring isotope enrichment using the single pool model (48). Peripheral insulin sensitivity (M value) was calculated as the average glucose infusion rate during a 30-minute steady state of the hyperinsulinemic-euglycemic clamp and corrected for fat-free mass (49). Hepatic glucose production was calculated as the difference between the basal glucose rate of appearance and the glucose infusion rate during clamp steady state.

Power and sample size calculations. Power analyses were conducted a priori on the basis of data from previous human studies using leptindeficient and replacement models and indicated that a sample size of 10 subjects in each group (leptin initiation and leptin withdrawal) would provide $80 \%$ power to detect significant differences between the offversus on-metreleptin condition during constant food intake for the following primary and secondary outcomes: peripheral insulin sensitivity, hepatic insulin sensitivity, fasting plasma glucose, rate of lipolysis, and fasting triglycerides. Given the limited pool of subjects with lipodystrophy already taking metreleptin (leptin withdrawal cohort) who met the inclusion and exclusion criteria, we were unable to accrue the target sample size of 10 for this group.

Statistics. For all outcomes, normally distributed data are reported as the mean \pm SD. Non-normally distributed data are reported as the geometric mean [25th, 75th percentiles]. Measurements in each of the primary and secondary outcomes were analyzed to detect differences between period 1 and period 2 for each cohort (leptin initiation and leptin withdrawal). For the leptin initi- ation cohort, secondary analyses were conducted to detect differences between period 1 and 6-month follow-up and between period 2 and 6-month follow-up using both multiple paired comparisons and linear mixed models with Bonferroni correction for multiple comparisons for pairs of time points.

Data analysis for primary and secondary outcomes was performed without covariate adjustment and with covariate adjustment. The potential covariates included in each model were: the baseline (pre-diet) value for the outcome, age, sex, race, type of lipodystrophy (partial versus generalized, initiation cohort only), the endogenous leptin level prior to metreleptin treatment, and the measured mean caloric intake during period 1 and period 2 . For total body insulin sensitivity, additional models were used and included the above covariates plus BW, fat mass, and lean mass during the metreleptin-treated and untreated conditions. For both hepatic and total body insulin sensitivity, additional models were used and included the covariates of age, sex, and hepatic and intramyocellular triglyceride content (together and in separate models) during the metreleptin-treated and untreated conditions. For TEE, REE, and non-resting EE, the models included fat mass and lean body mass as covariates.

Unadjusted comparisons for each outcome were conducted using the paired $t$ test (for normally distributed variables) or the Wilcoxon paired test (for skewed variables). For adjusted comparisons for each outcome, a variable selection for the linear mixed model was used, and then a final linear mixed model with the selected covariates was used to compare time points. With a single exception, noted in the Results, the adjustment for covariates did not alter the statistical significance of any primary or secondary outcome. Therefore, only the unadjusted analyses are presented in the Results and figures. Linear mixed model analyses for covariateadjusted analysis are presented in Supplemental Tables 1-4. If significant differences were present in period 1 versus period 2 for an outcome in either the initiation or withdrawal cohort, we compared the delta between periods 1 and 2 for the 2 cohorts using a 2-sample $t$ test (for normally distributed variables) or a Mann-Whitney $U$ test (for skewed variables). Only differences that were statistically significant are mentioned in the Results.

For the 2 prespecified coprimary outcomes of total body insulin sensitivity and lipolysis (glycerol Ra), a $P$ value of less than 0.025 was considered statistically significant to account for multiple comparisons. No multiplicity corrections were used for secondary outcomes, and a $P$ value of less than 0.05 was considered statistically significant. All reported $P$ values are 2 sided. Data analysis was conducted using SAS software, version 9.4 (SAS Institute), and GraphPad Prism, version 7.0 (GraphPad Software).

Study approval. The IRB of the NIDDK approved this study. All patients or legal guardians for those under 18 years of age provided written informed consent before participation in the study, and minor participants provided written assent. This study is registered at ClinicalTrials.gov (NCT01778556).

\section{Author contributions}

RJ Brown initiated the investigation, led the clinical experiments, and wrote, reviewed, and edited the manuscript. AV obtained and analyzed the data and wrote, edited, and reviewed the manuscript. MS obtained data and wrote, edited, and reviewed the 
manuscript. EC obtained data and edited and reviewed the manuscript. AMG and RO obtained and interpreted the MRS data and reviewed and edited the manuscript. RJ Brychta and KYC obtained and interpreted the energy expenditure data and reviewed and edited the manuscript. PJW, HMG, HC, and MW obtained data and edited and reviewed the manuscript. ABC and SB designed and implemented the controlled study diet and reviewed and edited the manuscript. SA provided statistical guidance prior to study implementation, conducted statistical analyses, and edited and reviewed the manuscript. PG contributed to the design of the study and reviewed and edited the manuscript. All authors gave final approval of the manuscript version to be published.

\section{Acknowledgments}

This study was supported by the intramural research program of the NIDDK. We thank the nurses at the Metabolic Unit of the NIH Clinical Center for their excellent patient care. Metreleptin was donated for this study by Aegerion Pharmaceuticals. This study would not have been possible without the altruism of our patients and their families, who devoted their time and energy to help us enhance scientific knowledge.

Address correspondence to: Rebecca J. Brown, Room 6-5940, Building 10, 10 Center Drive, Bethesda, Maryland 20814, USA. Phone: 301.594.0609; Email: .
1. Friedman JM, Halaas JL. Leptin and the regulation of body weight in mammals. Nature. 1998;395(6704):763-770.

2. Chin-Chance C, Polonsky KS, Schoeller DA. Twenty-four-hour leptin levels respond to cumulative short-term energy imbalance and predict subsequent intake. J Clin Endocrinol Metab. 2000;85(8):2685-2691.

3. Moran SA, et al. Changes in body composition in patients with severe lipodystrophy after leptin replacement therapy. Metab Clin Exp. 2004;53(4):513-519.

4. Diker-Cohen T, Cochran E, Gorden P, Brown RJ. Partial and generalized lipodystrophy: comparison of baseline characteristics and response to metreleptin. JClin Endocrinol Metab. 2015;100(5):1802-1810.

5. Safar Zadeh E, et al. The liver diseases of lipodystrophy: the long-term effect of leptin treatment. J Hepatol. 2013;59(1):131-137.

6. Moran SA, et al. Changes in body composition in patients with severe lipodystrophy after leptin replacement therapy. Metab Clin Exp. 2004;53(4):513-519.

7. Petersen KF, et al. Leptin reverses insulin resistance and hepatic steatosis in patients with severe lipodystrophy. JClin Invest. 2002;109(10):1345-1350.

8. Lungu AO, Zadeh ES, Goodling A, Cochran E, Gorden P. Insulin resistance is a sufficient basis for hyperandrogenism in lipodystrophic women with polycystic ovarian syndrome. JClin Endocrinol Metab. 2012;97(2):563-567.

9. Abel BS, Muniyappa R, Stratton P, Skarulis MC, Gorden P, Brown RJ. Effects of Recombinant Human Leptin (Metreleptin) on Nocturnal Luteinizing Hormone Secretion in Lipodystrophy Patients. Neuroendocrinology. 2016;103 (3-4):402-407.

10. Schwartz MW, et al. Specificity of leptin action on elevated blood glucose levels and hypothalamic neuropeptide Y gene expression in ob/ob mice. Diabetes. 1996;45(4):531-535.

11. Shimomura I, Hammer RE, Ikemoto S, Brown MS, Goldstein JL. Leptin reverses insulin resistance and diabetes mellitus in mice with congenital lipodystrophy. Nature. 1999;401(6748):73-76.

12. McDuffie JR, et al. Effects of exogenous leptin on satiety and satiation in patients with lipodystrophy and leptin insufficiency. J Clin Endocrinol Metab. 2004;89(9):4258-4263.

13. Oral EA, et al. Leptin-replacement therapy for lipo- dystrophy. NEngl JMed.2002;346(8):570-578.

14. Vatier C, et al. One-year metreleptin improves insulin secretion in patients with diabetes linked to genetic lipodystrophic syndromes. Diabetes Obes Metab. 2016;18(7):693-697.

15. Ebihara K, et al. Efficacy and safety of leptinreplacement therapy and possible mechanisms of leptin actions in patients with generalized lipodystrophy. JClin Endocrinol Metab. 2007;92(2):532-541.

16. Shi ZQ, Nelson A, Whitcomb L, Wang J, Cohen AM. Intracerebroventricular administration of leptin markedly enhances insulin sensitivity and systemic glucose utilization in conscious rats. Metab Clin Exp. 1998;47(10):1274-1280.

17. Rouru J, Cusin I, Zakrzewska KE, Jeanrenaud B, Rohner-Jeanrenaud F. Effects of intravenously infused leptin on insulin sensitivity and on the expression of uncoupling proteins in brown adipose tissue. Endocrinology. 1999;140(8):3688-3692.

18. Perry RJ, Samuel VT, Petersen KF, Shulman GI. The role of hepatic lipids in hepatic insulin resistance and type 2 diabetes. Nature. 2014;510(7503):84-91.

19. Korenblat KM, Fabbrini E, Mohammed BS, Klein S. Liver, muscle, and adipose tissue insulin action is directly related to intrahepatic triglyceride content in obese subjects. Gastroenterology. 2008;134(5):1369-1375.

20. Hwang JH, et al. Increased intrahepatic triglyceride is associated with peripheral insulin resistance: in vivo MR imaging and spectroscopy studies. Am J Physiol Endocrinol Metab. 2007;293(6):E1663-E1669.

21. Hernández EÁ, et al. Acute dietary fat intake initiates alterations in energy metabolism and insulin resistance. J Clin Invest. 2017;127(2):695-708.

22. D'Adamo E, et al. Central role of fatty liver in the pathogenesis of insulin resistance in obese adolescents. Diabetes Care. 2010;33(8):1817-1822.

23. Perry RJ, et al. Reversal of hypertriglyceridemia, fatty liver disease, and insulin resistance by a livertargeted mitochondrial uncoupler. Cell Metab. 2013;18(5):740-748.

24. Farooqi IS, et al. Effects of recombinant leptin therapy in a child with congenital leptin deficiency. NEngl JMed.1999;341(12):879-884.

25. Rosenbaum M, et al. Low-dose leptin reverses skeletal muscle, autonomic, and neuroendocrine adaptations to maintenance of reduced weight. J Clin Invest. 2005;115(12):3579-3586.
26. Rosenbaum M, Murphy EM, Heymsfield SB, Matthews DE, Leibel RL. Low dose leptin administration reverses effects of sustained weightreduction on energy expenditure and circulating concentrations of thyroid hormones. JClin Endocrinol Metab. 2002;87(5):2391-2394.

27. Ravussin E, et al. Thermic effect of infused glucose and insulin in man. Decreased response with increased insulin resistance in obesity and noninsulin-dependent diabetes mellitus. JClin Invest. 1983;72(3):893-902.

28. Veldhorst MA, Westerterp-Plantenga MS, Westerterp KR. Gluconeogenesis and energy expenditure after a high-protein, carbohydrate-free diet. Am J Clin Nutr. 2009;90(3):519-526.

29. Shannon JR, et al. Acute effect of ephedrine on 24-h energy balance. Clin Sci. 1999;96(5):483-491.

30. Prieur X, Tung YC, Griffin JL, Farooqi IS, O'Rahilly S, Coll AP. Leptin regulates peripheral lipid metabolism primarily through central effects on food intake. Endocrinology. 2008;149(11):5432-5439.

31. Donahoo WT, Stob NR, Ammon S, Levin N, Eckel RH. Leptin increases skeletal muscle lipoprotein lipase and postprandial lipid metabolism in mice. Metab Clin Exp. 2011;60(3):438-443.

32. Cohen $\mathrm{P}$, et al. Role for stearoyl-CoA desaturase-1 in leptin-mediated weight loss. Science. 2002;297(5579):240-243.

33. Minokoshi Y, et al. Leptin stimulates fatty-acid oxidation by activating AMP-activated protein kinase. Nature. 2002;415(6869):339-343.

34. Steinberg GR, Dyck DJ. Development of leptin resistance in rat soleus muscle in response to high-fat diets. Am J Physiol Endocrinol Metab. 2000;279(6):E1374-E1382.

35. Siegrist-Kaiser CA, et al. Direct effects of leptin on brown and white adipose tissue. JClin Invest. 1997;100(11):2858-2864.

36. Wang MY, Lee Y, Unger RH. Novel form of lipolysis induced by leptin. J Biol Chem. 1999;274(25):17541-17544.

37. Frühbeck G, Aguado M, Gómez-Ambrosi J, Martínez JA. Lipolytic effect of in vivo leptin administration on adipocytes of lean and ob/ob mice, but not db/db mice. Biochem Biophys Res Commun. 1998;250(1):99-102.

38. Shimabukuro M, et al. Direct antidiabetic effect of leptin through triglyceride depletion of tissues. Proc Natl Acad Sci U S A. 1997;94(9):4637-4641.

39. Zeng W, et al. Sympathetic neuro-adipose connections mediate leptin-driven lipolysis. Cell. 


\section{CLINICAL MEDICINE}

The Journal of Clinical Investigation

2015;163(1):84-94.

40. Heymsfield SB, et al. Recombinant leptin for weight loss in obese and lean adults: a randomized, controlled, dose-escalation trial. JAMA. 1999;282(16):1568-1575.

41. Zelissen PM, et al. Effect of three treatment schedules of recombinant methionyl human leptin on body weight in obese adults: a randomized, placebo-controlled trial. Diabetes Obes Metab. 2005;7(6):755-761.

42. Shetty GK, et al. Leptin administration to overweight and obese subjects for 6 months increases free leptin concentrations but does not alter circulating hormones of the thyroid and IGF axes during weight loss induced by a mild hypocaloric diet. Eur JEndocrinol. 2011;165(2):249-254.

43. Hukshorn CJ, Saris WH, Westerterp-

Plantenga MS, Farid AR, Smith FJ, Campfield

LA. Weekly subcutaneous pegylated recombinant native human leptin (PEG-OB) administration in obese men. JClin Endocrinol Metab. 2000;85(11):4003-4009.

44. Brychta RJ, Rothney MP, Skarulis MC, Chen KY. Optimizing energy expenditure detection in human metabolic chambers. Conf Proc IEEE Eng Med Biol Soc. 2009;2009:6864-6868.

45. Ouwerkerk R, Pettigrew RI, Gharib AM. Liver metabolite concentrations measured with $1 \mathrm{H} M \mathrm{MR}$ spectroscopy. Radiology. 2012;265(2):565-575.

46. Muniyappa R, et al. Myocardial Fat Accumulation
Is Independent of Measures of Insulin Sensitivity. JClin Endocrinol Metab. 2015;100(8):3060-3068.

47. Walter PJ, Garraffo HM, Chung S, Brown R. Mass spectrometry and allied topics. Presented at the 65th ASMS conference on mass spectrometry and allied topics; June 4-8, 2017; Indianapolis, IN.

48. Wolfe R, Chinkes DL. Isotopic tracers in metabolic research: principles and practice of kinetic analysis. Hoboken, New Jersey: John Wiley \& Sons Inc.; 2005.

49. DeFronzo RA, Tobin JD, Andres R. Glucose clamp technique: a method for quantifying insulin secretion and resistance. Am J Physiol. 1979;237(3):E214-E223. 